Vol.: 5 Issue: 2 Date: 31.12.2021 Received: 15.12.2021 Accepted: 30.12.2021 Final Version: 31.12.2021

ISVOS Journal, 2021, 5(2): 266-274 - https://doi.org/10.47897/bilmes.751995

\title{
Drawing the Building TAKS Boundaries with the Help of the Sine Theorem of Planned Type Zoning Building Regulations
}

\author{
Selim TAŞKAYA ${ }^{\mathrm{a}, 1}$ \\ aArtvin Çoruh Üniversitesi Artvin Meslek Yüksekokulu Mimarlik Ve Şehir Planlama Bölümü, Artvin, Türkiye \\ ORCID ID: 0000-0002-4290-3684
}

\begin{abstract}
Zoning plans are the design work required for the correct use of space in terms of urbanization. While creating zoning plans, zoning islands are created together with various planning methods. Reconstruction islands are also named as having legends such as residence, subject + commercial, commercial, social areas, religious facility areas called places of worship, green areas. The important part is how the construction permit is given to the parcels that will coincide within these islands. This process is the zoning diameter. Zoning diameters are the drawings made on the ground according to different methods. In our study of how to give zoning diameters to different types of zoning islands, it was aimed to provide appropriate angle distances inside perpendicular or parallel by adding the lengths of the parcels to each other, which we call the sine theorem. It was examined how the zoning island would be given a diameter in terms of length according to the precedent and the amount of height processed in the plan.
\end{abstract}

Keywords: "Zoning Structure Ordinance, Sine Theorem, Zoning Diameter"

\section{Introduction}

Zoning Law, which is directly related to fundamental rights and freedoms, brings regulations in areas that are closely related to the society such as the right to property, the right to life and the freedom of settlement. If we look at it from a broad perspective, zoning law restricts some fundamental rights and freedoms, but in practice, its scope includes issues that require more expertise. As can be understood from the definition, all public and private public works activities are included in the areas regulated by the zoning law [3]. When we look at the legislation within the scope of the zoning law, we encounter a wide variety of laws. The first of these is the Zoning Law No. 3194. In article 2 of the Zoning Law, the scope of the law is mentioned and it is stated that all buildings to be built within or outside the borders of the municipality and the adjacent area are subject to this law. The Municipal Law No. 5393 covers the municipalities according to art.1 and art.2, but also regulates their working procedures and principles, duties and authorities. Likewise, the Metropolitan Municipality Law No. 5216 covers metropolitan municipalities and aims to provide planned and efficient services by regulating the legal status of metropolitan municipalities. Article 2 of the Soil Conservation and Land Use Law No. 5403 covers the issues of arranging land and soil resources in accordance with scientific principles and determining measures for the protection of the land [8]. Although the main purpose of planning is livable cities and therefore public benefit, the regulations to be made create some obligations and obligations not only for the institutions authorized to make this regulation, but also for the individuals [9]. Planning, as a concept, is a way of thinking that is thought ahead from a certain moment; It is the sum of the studies aimed at examining the possibilities, possibilities, comparison activities, and establishing regular relations between individuals and their communities and their environment [6]. It is aimed to implement zoning and urban planning activities in line with the principles of honesty and compliance in the light of laws and regulations, by transforming them into implementation plans of 1000 by local governments [10]. Rapid urbanization has brought about unplanned development. This process has revealed an urban texture where social and technical equipment areas are insufficient, transportation planning cannot be made, and industrial facilities are intertwined with living and resting areas [11].

\section{Material and Methods}

We mentioned in the introduction that symmetry is actually a transformation and that we can call this transformation symmetry under some conditions. These conditions are; being diffeomorphism, preserving the structure and mapping the of the element to itself. As an example of a geometric shape, we have an equilateral triangle at the previous chapter. As Peter Hydon explains in his book these examples can be multiplied. For example, if we examine the symmetries of the unit circle [16]. These 4 transformations that we have given as examples satisfy the conditions of symmetry. So the new $\mathrm{x}$ and y can be differentiable at any point,

${ }^{1}$ Corresponding author. Tel: +904662151055

E-mail address: selim_taskaya@artvin.edu.tr 
furthermore the inverse of $\phi 1, \phi 2, \phi 3, \phi 4$ also are the symmetry transformations. So it is clear that the transformations are diffeomorphisms and at the same time they maintain the form [15].

$$
\begin{gathered}
\phi 1:(\mathrm{x}, \mathrm{y}) \rightarrow(-\mathrm{x}, \mathrm{y}) \\
\phi 2:(\mathrm{x}, \mathrm{y}) \rightarrow(\mathrm{x},-\mathrm{y}) \\
\phi 3:(\mathrm{x}, \mathrm{y}) \rightarrow(-\mathrm{x},-\mathrm{y}) \\
\phi 4:(\mathrm{x}, \mathrm{y}) \rightarrow(\mathrm{x} \cos \mathrm{a}-\mathrm{y} \sin \mathrm{a}, \mathrm{y} \sin \mathrm{a}+\mathrm{x} \cos \mathrm{a})
\end{gathered}
$$

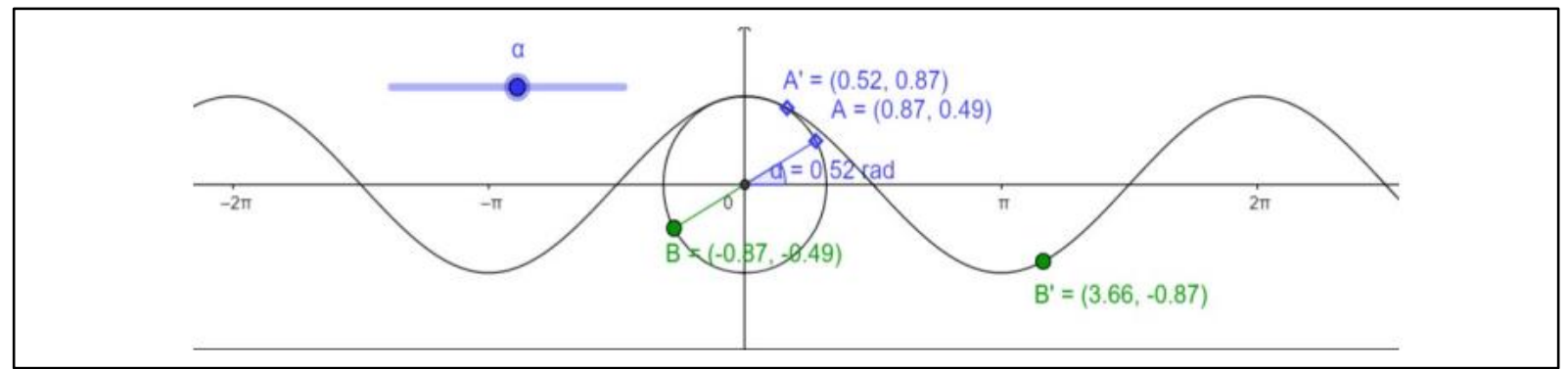

Figure 1. Sine Graph [15].

For each $\mathrm{a} \in(-\pi, \pi]$. Here a will be the continuous parameter, which we will define later. We will study with the Lie group created by the transformations. When a equals to $0, \phi 4$ will be a trivial symmetry of the unit circle. Since trivial symmetries will not help to find another solution, we will not deal with them in our research. The transformations $\phi 1, \phi 2, \phi 3, \phi 4$ are symmetry transformations for the unit circle [15].

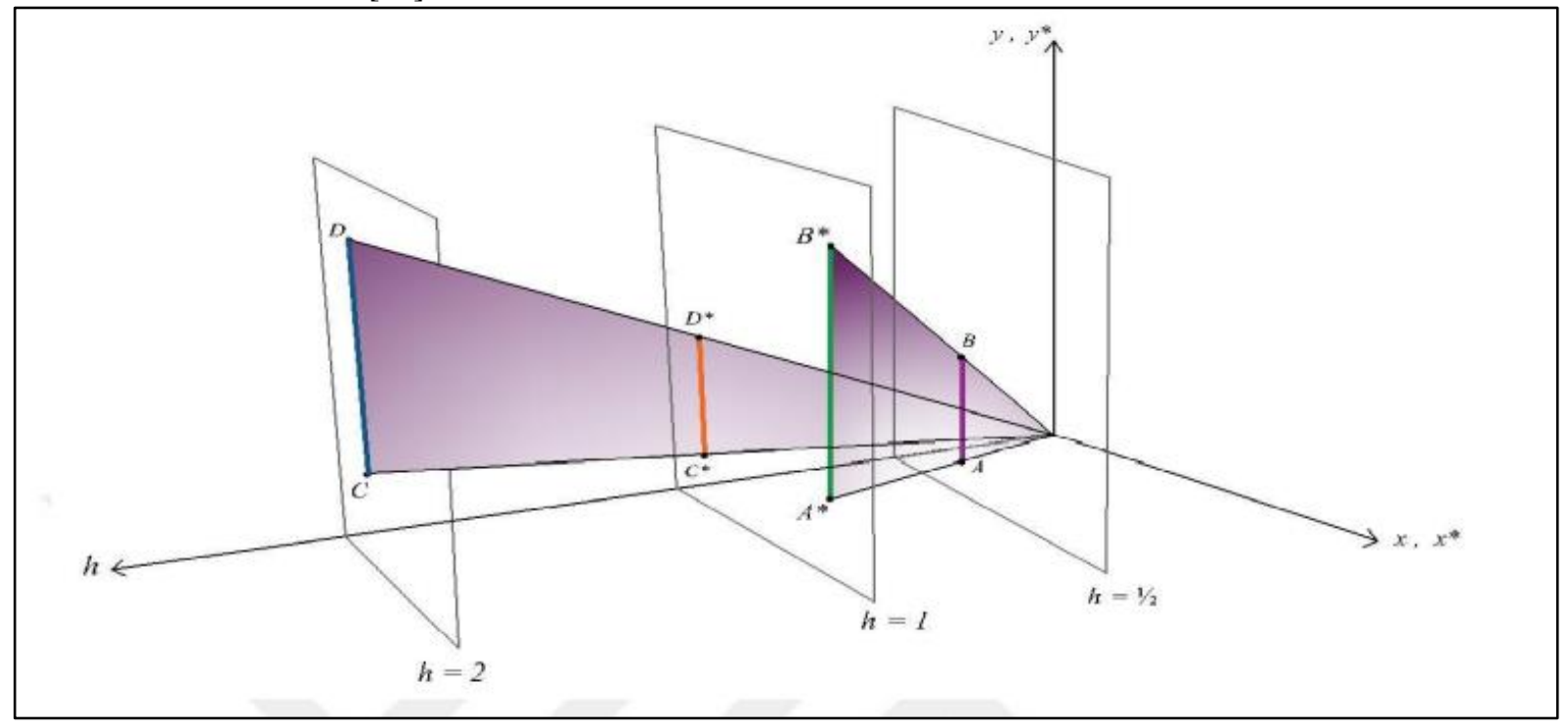

Figure 2. A geometric interpretation of general scaling [4].

Homogeneous coordinates provide a convenient and efficient technique for mapping a set of points from one coordinate system to a corresponding set in an alternate coordinate system. Frequently, an infinite range in one coordinate system matches a finite range in an alternative coordinate system [4]. Parallel lines may not match parallel lines unless pairings are carefully chosen. However, intersection points can be mapped to intersection points. This property is used to specify the homogeneous coordinate representation of a point at infinity $[1 ; 2 ; 5]$.

\section{Results and Discussion}

In order for citizens or official institutions to build on a land, they have to get permission from the municipalities within the boundaries of the municipality's zoning and adjacent area, and from the special provincial administrations outside the boundaries of the municipality's zoning and adjacent areas [7;12]. If it is a cadastral parcel, the relevant immovable, that is, if the application of the 18th article and the unification of the land, its abandonment to the road or its creation from the road have not been made, the construction permit cannot be granted in its current state [7]. If the parcel is in the shape of the land within the normal zoning limits, and if it is outside the zoning boundaries, it is allowed for construction if it has a frontage to at least one road and is not abandoned or formed [7;12].

Regardless of the type of construction, residential, commercial, industrial, residential+trade or vineyard areas outside the zoning borders, or whatever will be done outside the zoning contiguous borders, the first step of the process is the zoning scale. Zoning diameter is the process of giving the drawing distances in accordance with the building regulation, in the national coordinate or local coordinate system, within the framework of the planned type or unplanned type areas regulation. After the zoning diameter 
is given to a plot, the project phase is started. The basic initial zoning diameter for construction in a place is [13].

Zoning diameters are given in 3 main axes as separate, adjacent and in block order. The drawing distances are given according to the construction order of the plan, where the front, depth and corner coordinates and the raw data obtained from the current land coincide on the plan [12]. According to the mechanical results among them, shape changes, knot and vector analyzes can be examined and compared [14]. The same structures with the same geometric shapes and different supports and different geometric shapes were compared and examined [14].

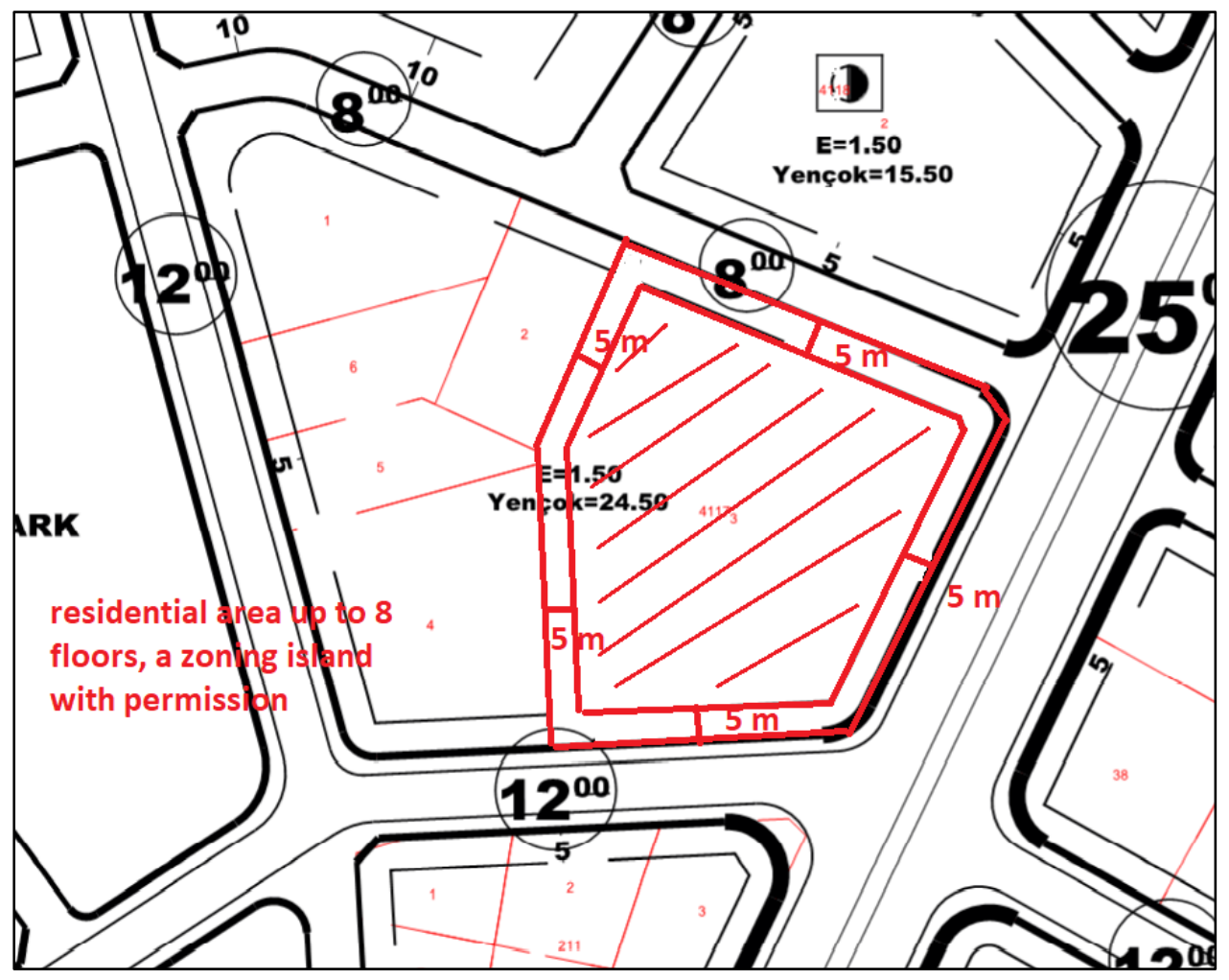

Figure 3. 8-storey residential area zoning diameter view

In Figure 3, the immovable is an island with a separate structure. Its maximum height is 24.50 meters and the total construction area is 1.50 . The total construction area is found by multiplying the title deed area. With the help of the theorem of sines, the front drawing distance from the angle and distance calculation was found by drawing 5 meters from the front facing fixed 3 sides. The distance to the side garden is 5 meters based on the maximum number of floors up to 8 floors, and the zoning diameter is given in the middle.

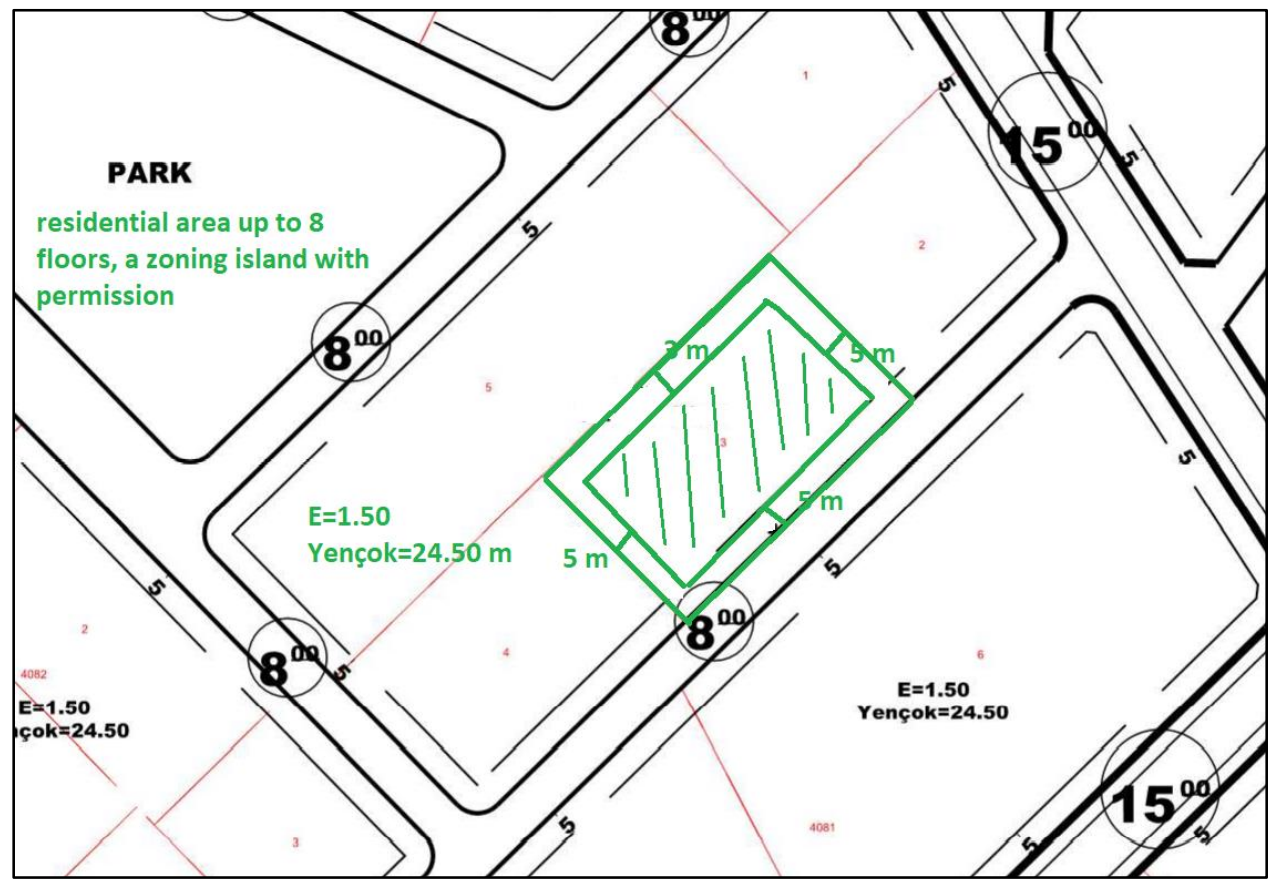

Figure 4. 8-storey residential area zoning diameter view 
In Figure 4., the relevant immovable parcel is a zoning parcel in the size of a single-sided separate order. It is allowed up to a maximum of 8 floors, and the total construction area is 1.5 times the title deed area. The front towing distance is 5 meters, the side garden is 3 meters in places up to 4 floors, and after 3 floors it will increase by half a meter per floor, since it will increase according to the regulation, it has been given 5 meters. Again, by making the angle and distance from the sine theorem, the minimum drawing distance of 3 meters is drawn and the zoning diameter is given in the middle.

5

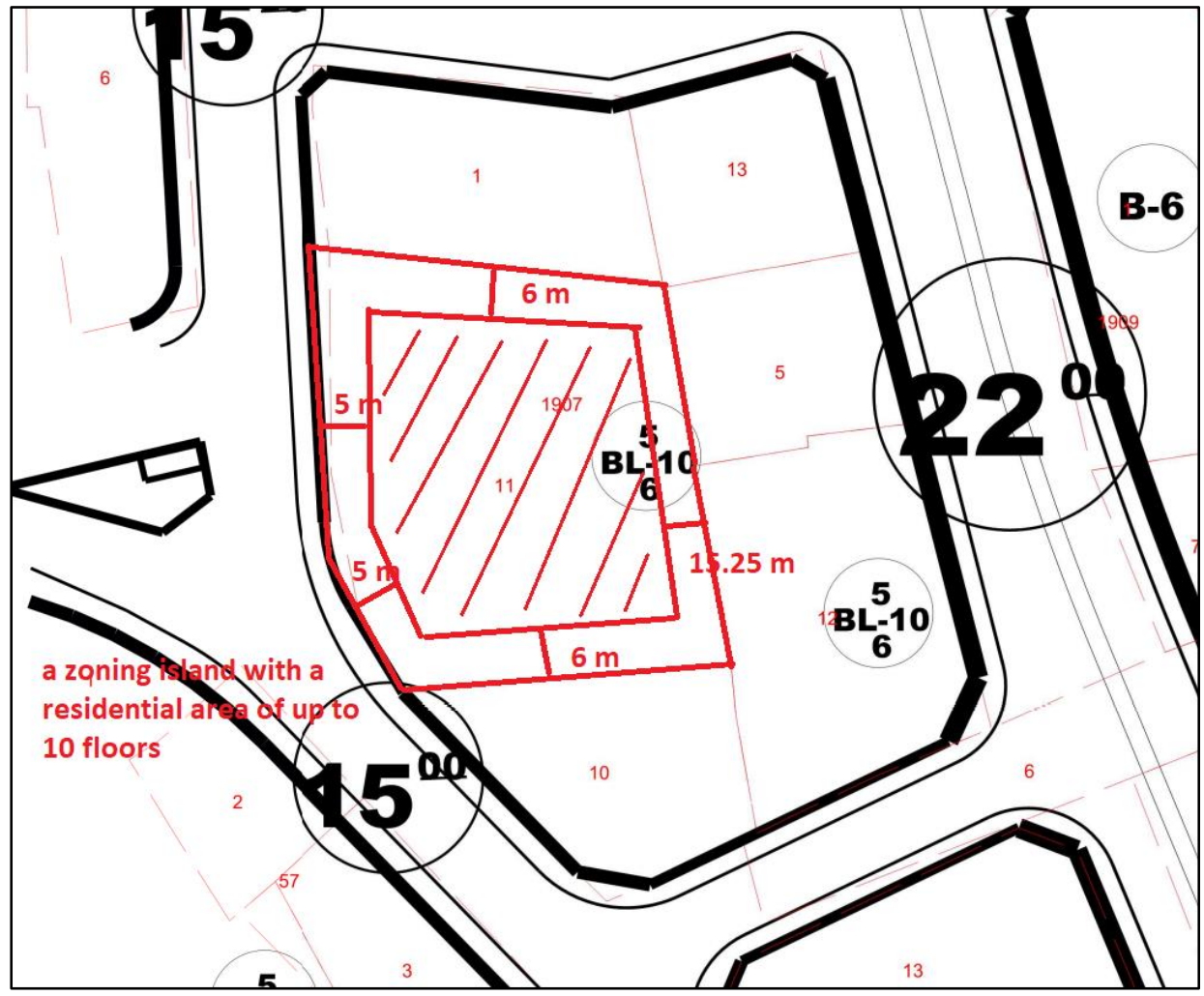

Figure 5. The zoning diameter view of the 10-storey residential area

In Figure 5, the relevant real estate is a parcel with a single side road border. Relevant zoning island residential area is allowed up to 8 floors apart. In places where the distance to the side garden is up to 4 floors, the floor sitting area is given by drawing a parallel line from the sinus angle technique of 6 meters by increasing 3 meters by half a meter after 4 floors. The amount of backyard is determined in parallel by taking the distance of the backyard as 3 meters per flat, taking 30 meters on a 10-storey floor, and taking half of it by adding the amount of eaves share at 0.5 meters.

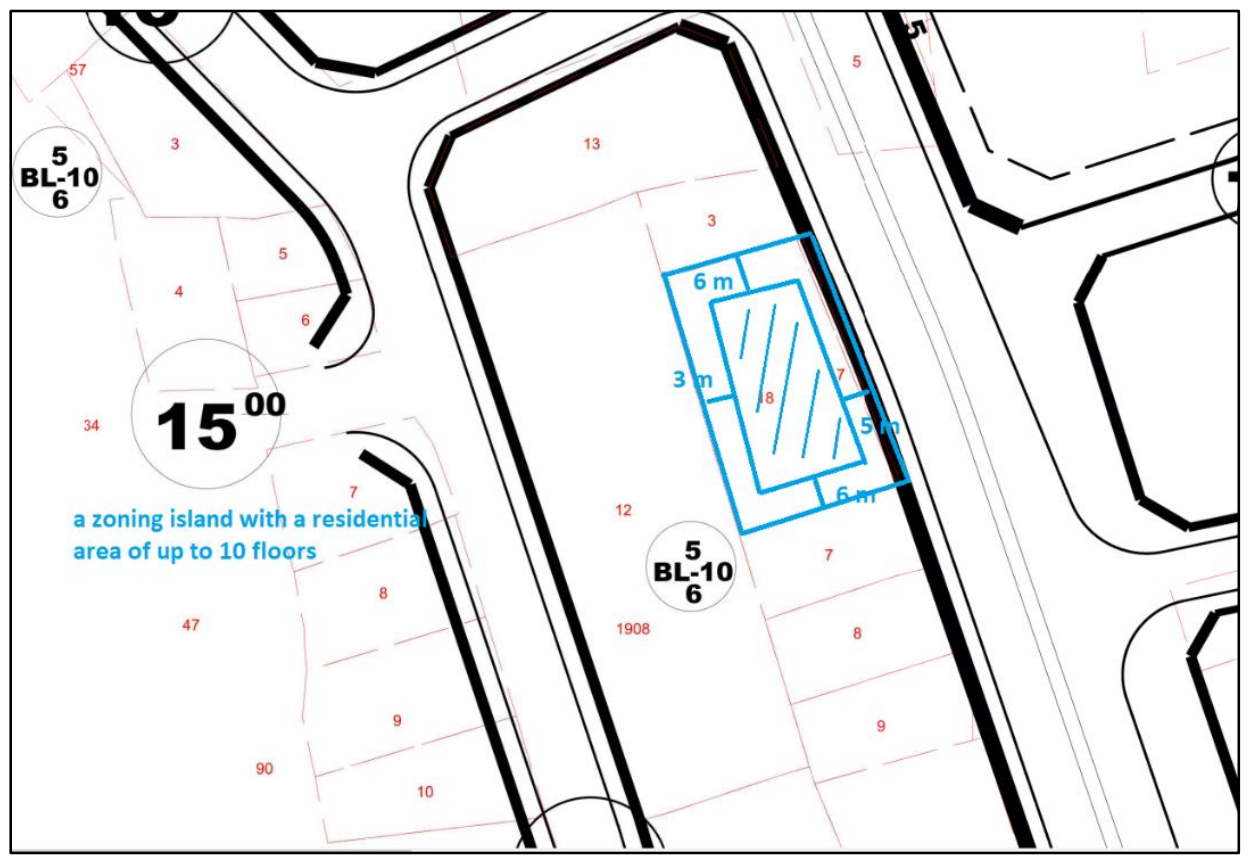


Figure 6. 8-storey residential area zoning diameter view

In Figure 6, the relevant immovable property is allowed up to 10 floors with a single façade, and the sitting limits of the building's residence area are determined by drawing 5 meters from the side facing the road and 6 meters from the side garden. The floor utilization coefficient is 0.30 , and the maximum use of the building floor is obtained by multiplying the title deed area by 0.30 .

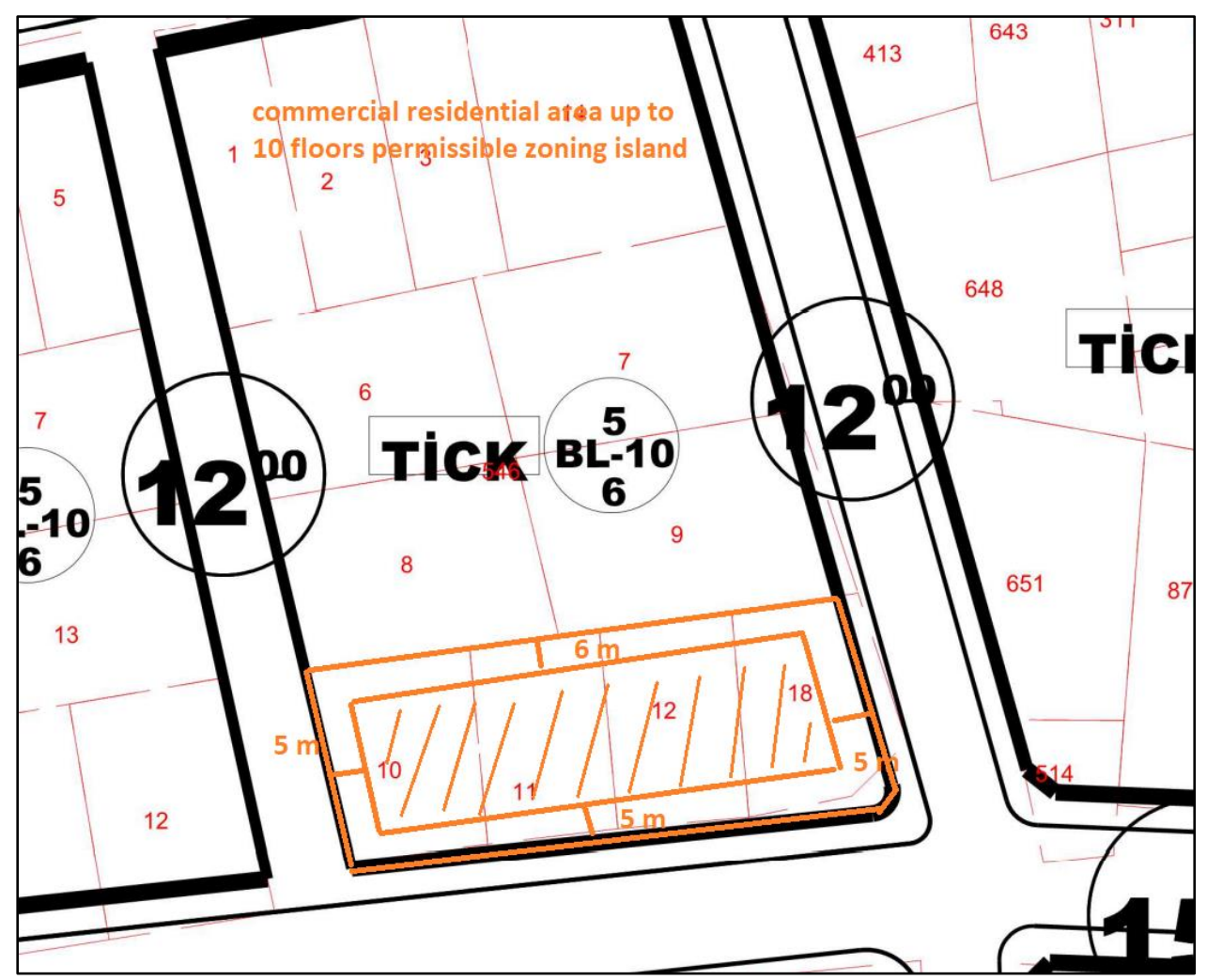

Figure 7. Zoning diameter view of a 10-storey commercial residential area

In Figure 7., the relevant immovable is allowed up to a maximum of 10 floors, the total construction area is 4.00 times the title deed area, and the front and side garden distances are parallel and the building floor sitting area is determined by drawing a triangle from sinus angles and distances by 5 meters. 


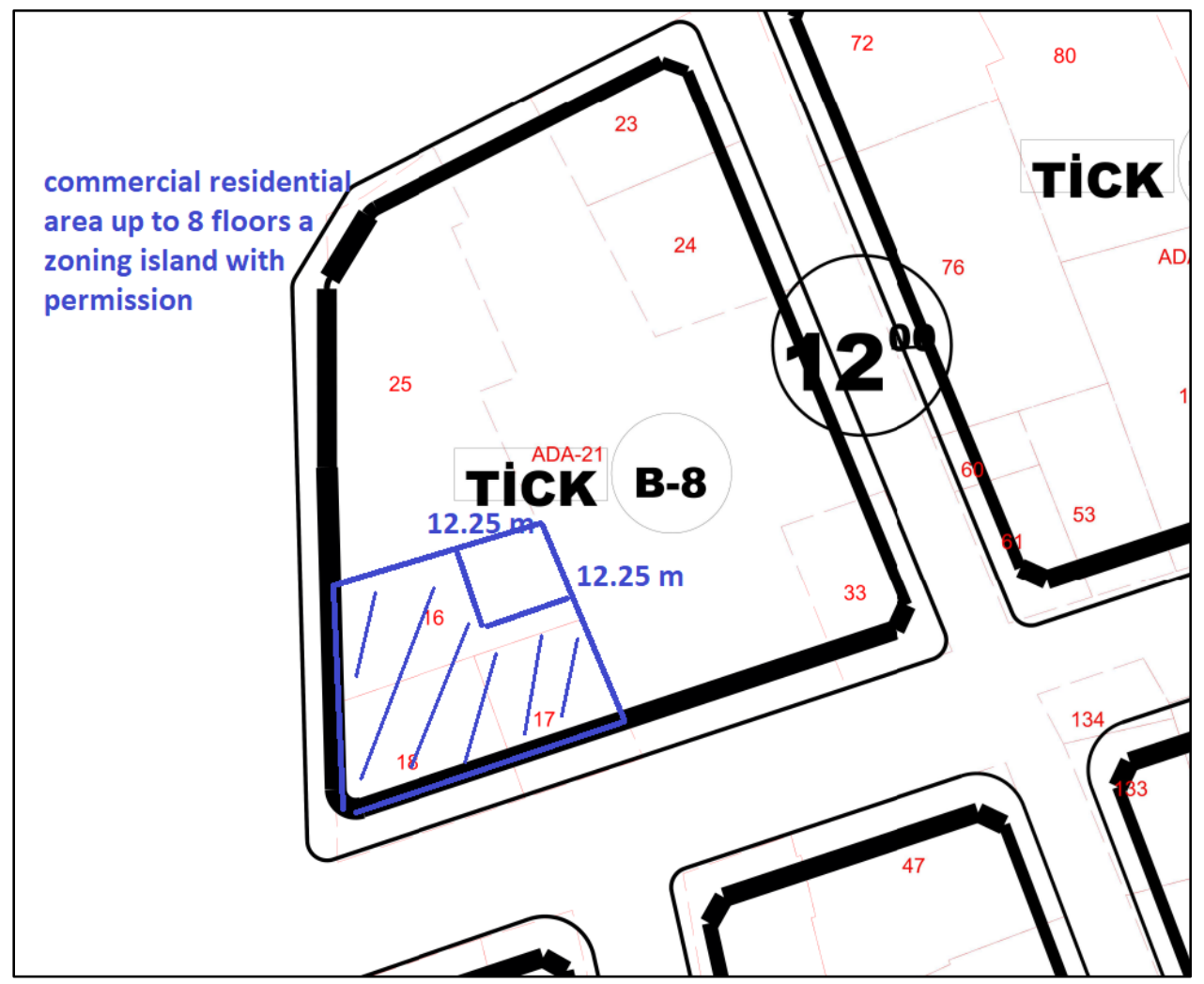

Figure 8. Zoning diameter view of 8-storey commercial residential area

In Figure 8., since the relevant real estate is located on an island with a maximum of 8 floors and is in a double-sided adjacent building order, the front towing distance was not applied. Instead, this area was created by pulling 12.25 meters, half of the height, which is the rear pull distance we call lighting.

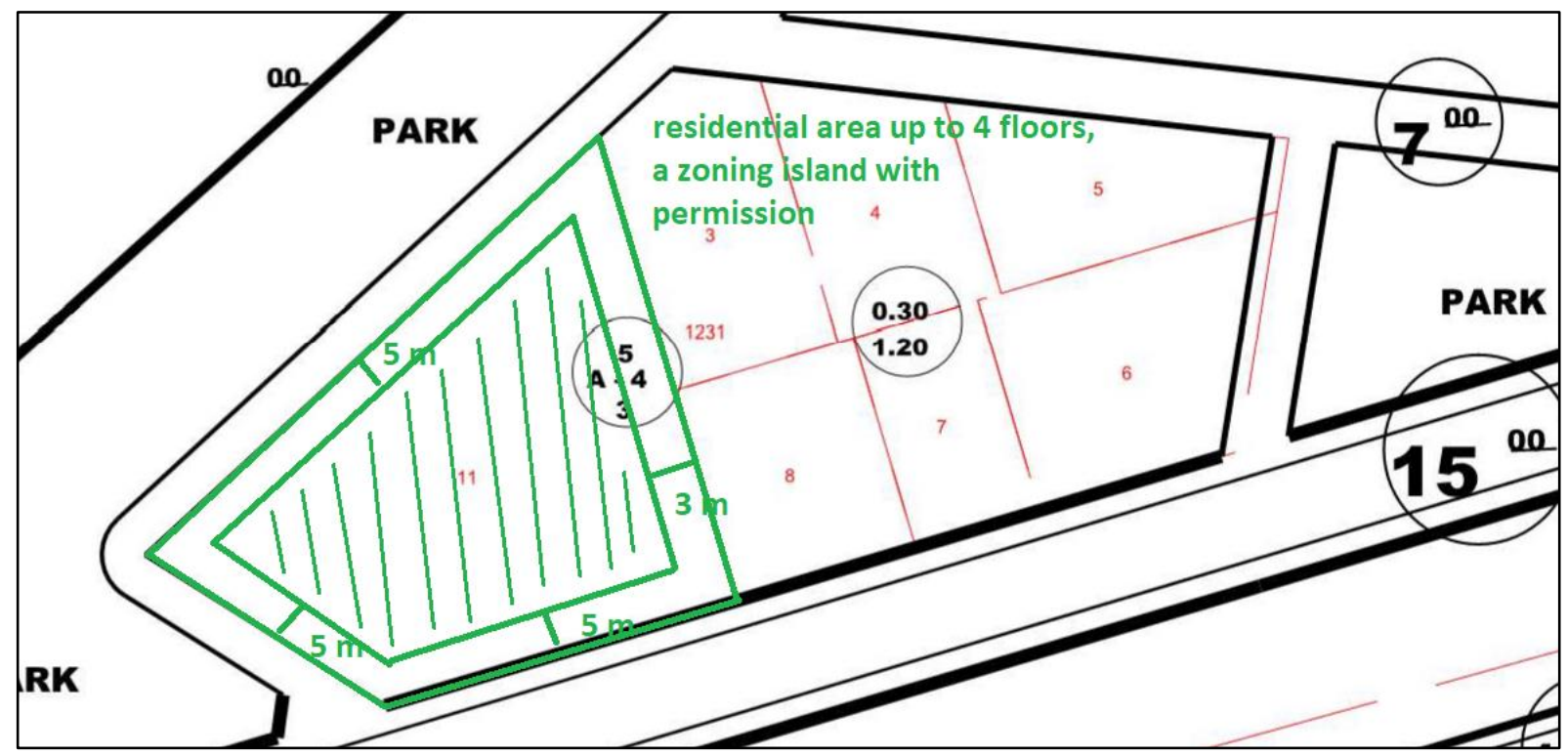

Figure 9. A view of the zoning diameter of the 4-storey residential area

In Figure 9, the relevant immovable is within the residential area. It is a parcel with a maximum of 4 floors, and the front garden distances are determined as 5 meters by drawing parallel. The zoning diameter is given in the middle by decreasing the amount of the side garden by 3 meters. 


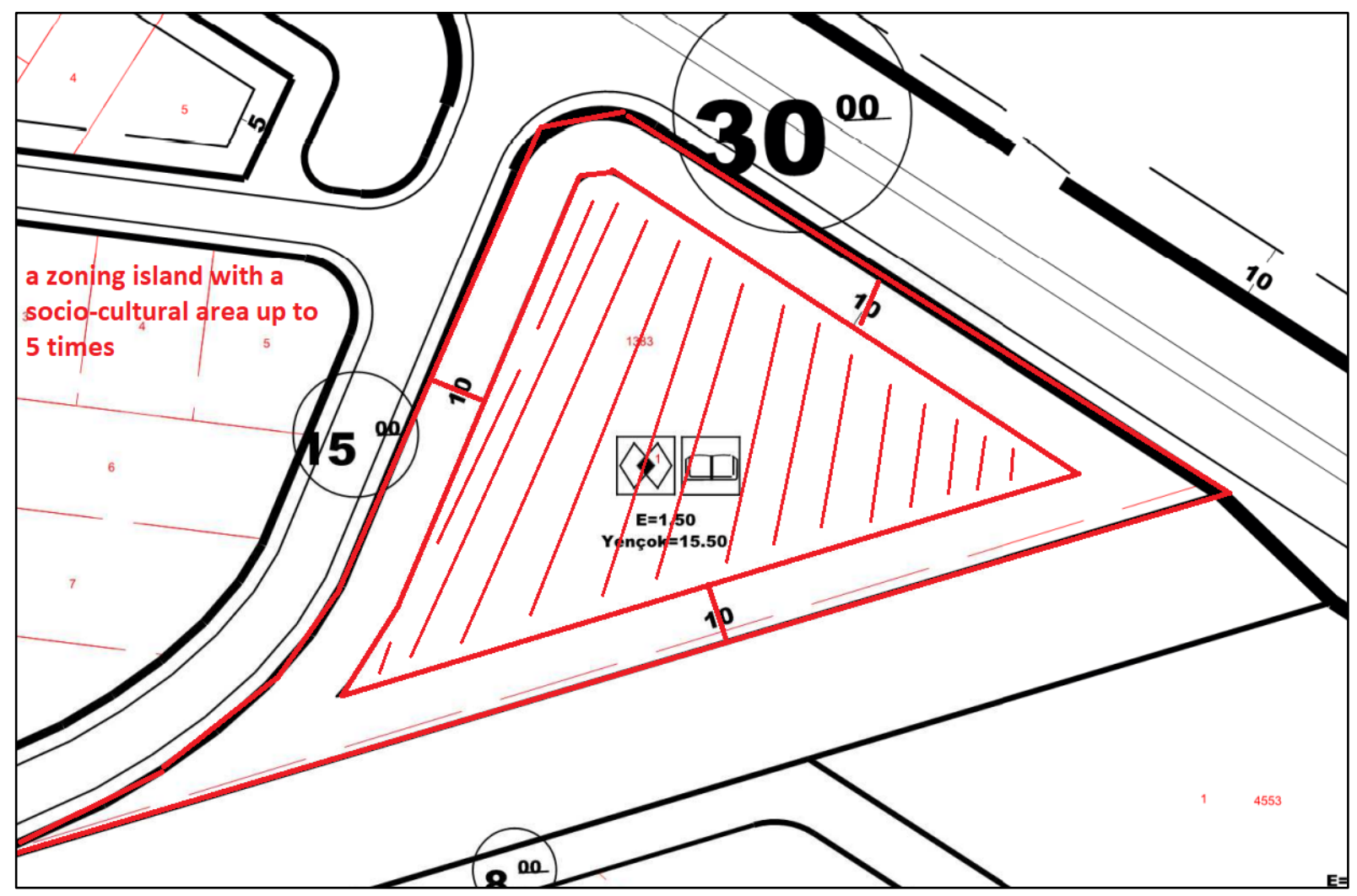

Figure 10. Zoning diameter view of the 5-storey social-cultural area

In Figure 10., the relevant area is a social cultural area with a maximum of 5 floors. The front towing distance is 10 meters each, and its equivalent is 1.5 . It is allowed up to a maximum of 15.50 meters.

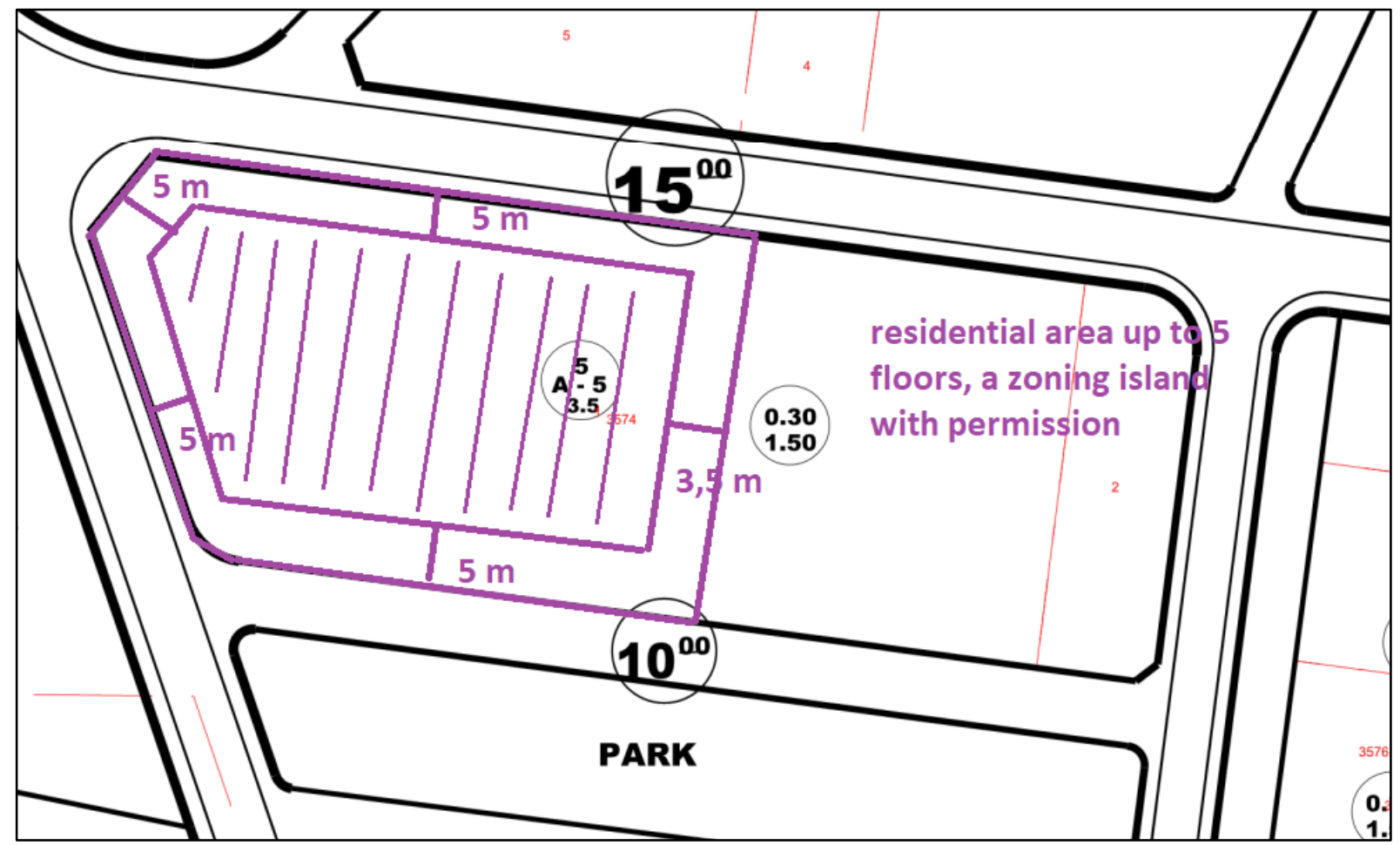

Figure 11. 5-storey residential area zoning diameter view

The real estate in Figure 11. is allowed up to 5 floors and its equivalent is 1.5. The front garden distance is 5 meters and the side garden distance is 3.5 meters, and the building sitting area is given in the middle. 


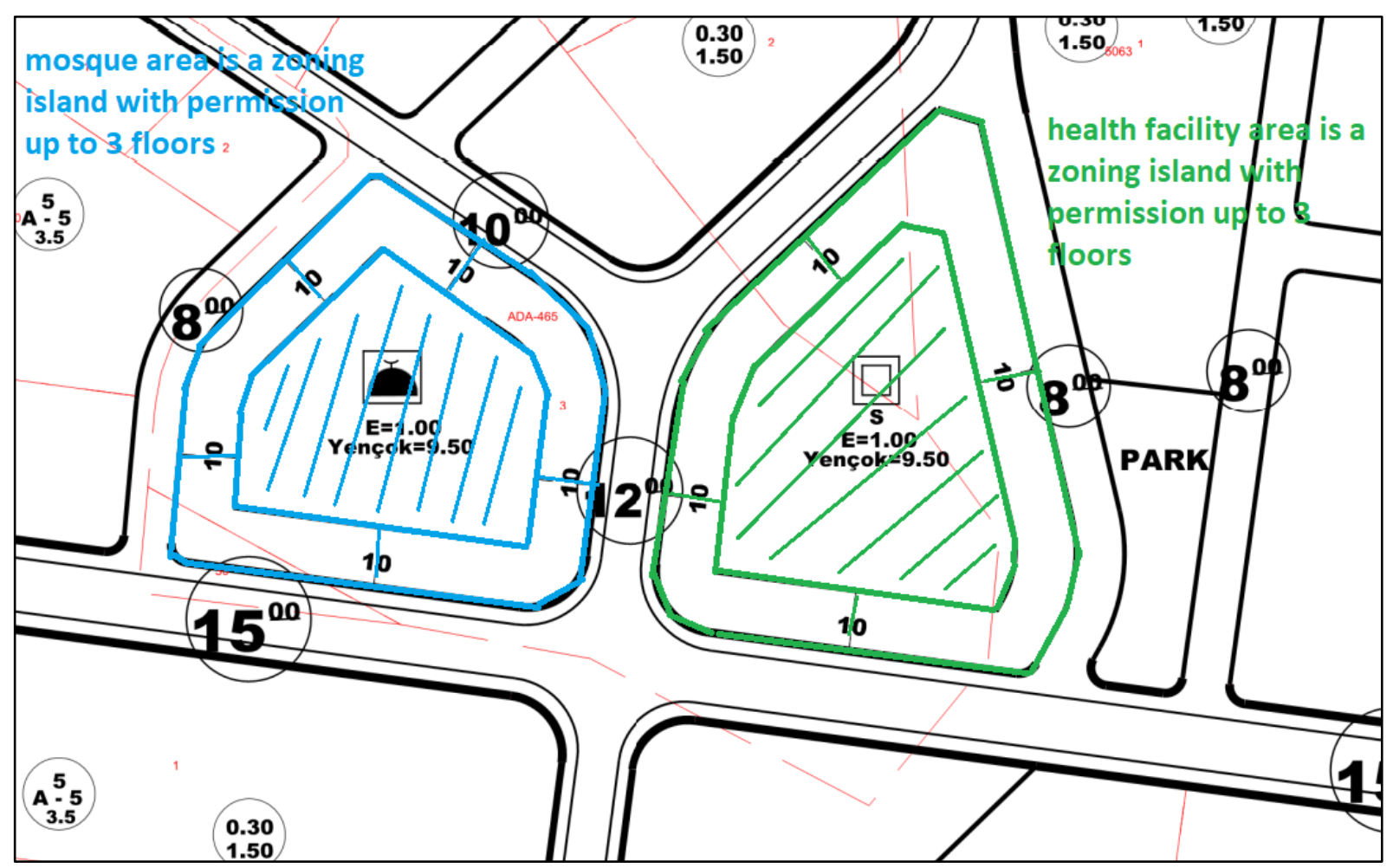

Figure 12. Image of the zoning diameter of the health facility and mosque area

Figure 12 shows how to give a zoning diameter to 2 zoning islands. The zoning diameters are given in the middle by drawing 10 meters from the facades of the parcels facing the whole road at the point that has been included in the plan as a health facility and mosque area. The maximum height of both zoning islands is up to 9.50 meters.

\section{Conclusions}

In the zoning plans, the zoning boundaries should be determined and the islands should be designed in a way that can meet the needs of all people from housing to commercial and social areas. In these areas, the purpose is to determine the areas where the building will be placed. This area determination job depends on the amount of population living in residential areas, and the correct provision of distance in commercial areas. The precedent of religious facility areas created in line with the amount of population and the floor areas to be used depend on this. In the findings section, the necessity of giving the construction diameters, which are visually indicated, from the sinus theorem, which is the length and angle technique as convex geometry, is discussed. In line with the planned type zoning regulation and plan notes, the application forms of the pulling distances are shown. Our suggestion, regardless of the area of the zoning diameter, whether the distance approach or the length addition technique, is to be formed in a way that will respond to the need by preventing the concrete from being concretized correctly.

\section{References}

[1] Applied Geometry for Computer Graphics and CAD. Springer-Verlag, London Berlin Heidelberg.

[2] Adams JA, Rogers DF, 1990. Mathematical Elements for Computer Graphics. McGraw Hill, USA.

[3] Aslantas, E; Simsek, G.F.; Berberoglu, O.A. Land and Land Arrangement in Zoning Law. Ankara: Yetkin Publications, 2006, p.17.

[4] Akagündüz Başköy,D.B., 2021. Geometric Transformations and Maple Applications, Master's Thesis in the Department of Mathematics.

[5] Gallier J, 1999. Curves and Surfaces in Geometric Modeling, Theory and Algorithms. morgan.

[6] The crowd, Khalil. Zoning Law Courses. Ankara: Seçkin Publishing, 2014, p.43

[7] Zoning Law, (2019). Official Gazette, Vol:24. Pages:1-378.

[8] Namlı Serin, B. 2017. Preparation and Implementation of Zoning Plans Master's Thesis, Baskent University Institute of Social 
Sciences, Department of Law, Public Law.

[9] Onar, S1dd1k Sami., 2014. General Principles of Administrative Law, C.II. Istanbul, 1966, p.1346; DAY, Text. Administrative law. Ankara: Image Publishing House, 2011, p.492,493; AKYILMAZ, Bahtiyar - SEZGINER, Murat - KAYA, Cemil. Turkish Administrative Law. Seçkin Publications, 2014, p.321

[10] Taşkaya, S., (2019). A Research on Reconstruction and Urbanization Activities in Local Governments, Municipality Between 2014-2019, The Case of Elazig Province. International Journal of Eastern Anatolia Science, Engineering and Design, 1(1), 14-28.

[11] Taşkaya, S., (2019). A Research on Zoning Diameters, which are the Basic Points for Construction Permits, International Journal of Eastern Anatolia Science, Engineering and Design, 1(2), 142-153.

[12] Taşkaya, S., Taşkaya, S., (2019). Measurement of Multi-Storey Buildings Using Workbench Module in ANSYS Package Software and Investigation of Prototype Analysis, International Journal of Engineering, Design and Technology 1(2): 51-63.

[13] Taşkaya, S., Taşkaya, S., (2019). Dimensioning of Coordinate Points of Two-Storey Building in Ansys Workbench Software and Investigation of Stress in Beams, International Journal on Mathematics, Engineering and Natural Sciences, 2019, vol:9 page:40-57.

[14] Taşkaya, S., Sesli, F.A., (2019). Power Test Analysis of Strategic and Local Spatial Data in Noise Pollution, Elazig Province İzzetpaşa Example, International Journal of Eastern Anatolia Science Engineering and Design ISSN: 2667-8764, International Journal of Eastern Anatolia Science Engineering and Design ( IJEASED) (2019) 1(1):1-13.

[15] Mendi, M., Lie Symmetry Analysis Of The Coupled System Of Sine-Gordon Equations, Master Of Science Thesis, 2021.

[16] Hydon, P. E., Symmetry Methos For Differential Equations. Cambridge University Press, Cambridge, 2000. 